\title{
REFLECTION
}

\section{From Triple to Quadruple Aim: Care of the Patient Requires Care of the Provider}

\author{
Thomas Bodenbeimer, $M D^{1}$ \\ Christine Sinsky, $M D^{2,3}$ \\ ${ }^{\prime}$ Center for Excellence in Primary Care, \\ Department of Family and Community \\ Medicine, University of California San \\ Francisco, San Francisco, California \\ ${ }^{2}$ Medical Associates Clinic and Health Plan, \\ Dubuque, lowa \\ ${ }^{3}$ American Medical Association, Chicago, \\ Illinois
}

Conflicts of interest: authors report none.

\section{CORRESPONDING AUTHOR}

Thomas Bodenheimer, MD

Center for Excellence in Primary Care Department of Family and Community Medicine

University of California at San Francisco Bldg 80-83, SF General Hospital

995 Potrero Ave. San Francisco, CA 94110 TBodenheimer@fcm.ucsf.edu or tbodie@ earthlink.net

\begin{abstract}
The Triple Aim-enhancing patient experience, improving population health, and reducing costs-is widely accepted as a compass to optimize health system performance. Yet physicians and other members of the health care workforce report widespread burnout and dissatisfaction. Burnout is associated with lower patient satisfaction, reduced health outcomes, and it may increase costs. Burnout thus imperils the Triple Aim. This article recommends that the Triple Aim be expanded to a Quadruple Aim, adding the goal of improving the work life of health care providers, including clinicians and staff.
\end{abstract}

Ann Fam Med 2014;12:573-576. doi: 10.1370/afm.1713.

\section{INTRODUCTION}

S ince Don Berwick and colleagues introduced the Triple Aim into the care system. The Triple Aim is an approach to optimizing health system performance, proposing that health care institutions simultaneously pursue 3 dimensions of performance: improving the health of populations, enhancing the patient experience of care, and reducing the per capita cost of health care. ${ }^{1}$ The primary Triple Aim goal is to improve the health of the population, with 2 secondary goals-improving patient experience and reducing costs-contributing to the achievement of the primary goal.

In visiting primary care practices around the country, ${ }^{2}$ the authors have repeatedly heard statements such as, "We have adopted the Triple Aim as our framework, but the stressful work life of our clinicians and staff impacts our ability to achieve the 3 aims." These sentiments made us wonder, might there be a fourth aim-improving the work life of health care clinicians and staff- that, like the patient experience and cost reduction aims, must be achieved in order to succeed in improving population health? Should the Triple Aim become the Quadruple Aim?

\section{RISING EXPECTATIONS OF PHYSICIANS AND PRACTICES}

Society expects more and more of physicians and practices, particularly in primary care. Patients want their health to be better, to be seen in a timely fashion with empathy, and to enjoy a continuous relationship with a high-quality clinician whom they choose. ${ }^{3}$ A patient-centered practice has been described as, "They give me exactly the help I need and want exactly when I need and want it." ${ }^{\prime \prime}$ Yet for primary care, society has not provided the resources to meet these lofty benchmarks.

\section{PHYSICIAN BURNOUT}

The wide gap between societal expectations and professional reality has set the stage for $46 \%$ of US physicians to experience symptoms of 
burnout. Widespread across specialties, burnout is especially prevalent among emergency department physicians, general internists, neurologists, and family physicians. ${ }^{5}$ In a 2014 survey, $68 \%$ of family physicians and $73 \%$ of general internists would not choose the same specialty if they could start their careers anew. ${ }^{6}$ Professional burnout is characterized by loss of enthusiasm for work, feelings of cynicism, and a low sense of personal accomplishment and is associated with early retirement, alcohol use, and suicidal ideation. ${ }^{5,7}$ According to a recent RAND Corporation survey, the principal driver of physician satisfaction is the ability to provide quality care. ${ }^{7}$ Physician dissatisfaction, therefore, is an early warning sign of a health care system creating barriers to high-quality practice.

We have heard physicians making such statements as:

"The joy of practicing medicine is gone."

"I hate being a doctor... I can't wait to get out."

"I can't tell you how defeated I feel...The feeling of being punished for delivering good care is nerve-racking."

"I am no longer a physician but the data manager, data entry clerk and steno girl... I became a doctor to take care of patients. I have become the typist."

In a 2011 national survey, $87 \%$ of physicians named the leading cause of work-related stress and burnout as paperwork and administration, with $63 \%$ indicating that stress is increasing. ${ }^{8}$ Forty-three percent of physicians surveyed in 2014 reported spending over $30 \%$ of their day on administrative tasks. ${ }^{9}$ Physicians spend more time on non-face-to-face activities (eg, letters, in-box management, and medication refills) than with patients..$^{10}$ Even when in the exam room with patients, primary care physicians spend from $25 \%$ to $50 \%$ of the time attending to the computer. ${ }^{11}$ Between 2009 and 2010, primary care physicians at a Veterans Affairs facility spent 49 minutes per day responding to inbox-type alerts in addition to documentation of care provided. One-half of such alerts have little clinical significance or could be handled by other team members; $80 \%$ of the text in the alerts is unnecessary. The volume of alerts and texts overshadows important information that requires action. Moreover, the alerts create interruptions known to adversely affect patient care. . $^{12,13}$

A 2013 survey of 30 physician practices found that electronic health record (EHR) technology has worsened professional satisfaction through time-consuming data entry and interference with patient care. ${ }^{7}$ Emergency medicine physicians spend $44 \%$ of their day doing data entry, with 4,000 EHR clicks per day; only $28 \%$ of the day is spent with patients. ${ }^{14}$ In a 2011 sur- vey, over three-quarters of physicians reported that the EHR increases the time it takes to plan, review, order, and document care. ${ }^{15}$

\section{STAFF BURNOUT}

Burnout affects not only physicians, but also other members of the health care workforce. Thirty-four percent of hospital nurses and $37 \%$ of nursing home nurses report burnout, compared with $22 \%$ of nurses working in other settings. ${ }^{16} \mathrm{On}$ the front lines of practice, receptionists have a stressful job, with $68 \%$ experiencing verbal abuse from patients. ${ }^{17}$ Most receptionists feel that physicians fail to appreciate the complexity of their work. Sources of stress include finding appointments for patients and feeling caught between doctors' and patients' demands. ${ }^{18}$ A 2013 survey of 508 employees working for 243 health care employers found that $60 \%$ reported job burnout and $34 \%$ planned to look for a different job. Complaints included heavy patient loads, small staffs, and high stress levels. ${ }^{19}$

Physician and staff dissatisfaction feed on each other. "It's really rough to be around a burned-out doctor. They're cynical, sarcastic, and wonder, 'what's the use anymore?"I It can go the other way, too. A burned-out staff member may not be doing his or her job, resulting in more stress for the already overworked doctor. ${ }^{20}$ Adequate numbers of well-trained, trusted, and capable support staff with low turnover predict greater physician satisfaction. ${ }^{7}$

\section{CARE TEAM WELL-BEING AS A PREREQUISITE FOR THE TRIPLE AIM}

Burnout among the health care workforce threatens patient-centeredness and the Triple Aim. Dissatisfied physicians and nurses are associated with lower patient satisfaction. ${ }^{16,21}$ Physician and care team burnout may contribute to overuse of resources and thereby increased costs of care. ${ }^{22-24}$ Unhappy physicians are more likely to leave their practice; the cost of family physician turnover approaches $\$ 250,000$ per physician. ${ }^{25}$ Dissatisfied physicians are more likely to prescribe inappropriate medications which can result in expensive complications. ${ }^{26}$

Physician burnout is associated with reduced adherence to treatment plans, resulting in negatively affected clinical outcomes. ${ }^{27}$ Burnout also leads to lower levels of empathy, which is associated with worsened clinical outcomes for patients with diabetes. ${ }^{28}$ Patient safety is threatened by nurse dissatisfaction; many nurses report that their workload causes them to miss important changes in their patients' condition. ${ }^{16}$ Dissatisfied physicians are 2 to 3 times more likely to 
leave practice, thereby exacerbating the growing shortage of primary care physicians and complicating the achievement of a healthy population. ${ }^{29}$

Practices working toward the Triple Aim may increase physician burnout and thereby reduce their chances of success. Higher scores on a patientcentered medical home assessment may be associated with greater clinician burnout in safety-net clinics. ${ }^{30}$ More EHR functionalities-email with patients, physician order entry, alerts and reminders-intended to promote the Triple Aim are associated with more burnout and intent to leave practice. ${ }^{31}$

Group Health Cooperative implemented primary care reforms in the early 2000s aimed at improving Triple Aim performance. The unintended consequence was increased physician burnout and resultant quality reductions and cost increases. In 2006, Group Health changed direction, focusing first on clinician work life by increasing visit length and reducing panel size. Burnout dropped substantially with significant gains in clinical quality, patient experience, and cost reduction. The Group Health story demonstrates that without addressing the work life of those providing care, Triple Aim measures are likely to worsen. ${ }^{32}$

\section{ADDRESSING THE FOURTH AIM}

How can health care organizations work toward the fourth aim, improving the work life of clinicians and staff? For primary care physicians the following list suggests some practical steps:

- Implement team documentation: nurses, medical assistants, or other staff, present during the patient visit, entering some or all documentation into the EHR, assisting with order entry, prescription processing, and charge capture. Team documentation has been associated with greater physician and staff satisfaction, improved revenues, and the capacity of the team to manage a larger panel of patients while going home earlier. ${ }^{33,34}$

- Use pre-visit planning and pre-appointment laboratory testing to reduce time wasted on the review and follow-up of laboratory results ${ }^{35}$

- Expand roles allowing nurses and medical assistants to assume responsibility for preventive care and chronic care health coaching under physician-written standing orders ${ }^{33,36}$

- Standardize and synchronize workflows for prescription refills, an approach which can save physicians 5 hours per week while providing better care ${ }^{37}$

- Co-locate teams so that physicians work in the same space as their team members; this has been shown to increase efficiency and save 30 minutes of physician time per day ${ }^{38}$
- To avoid shifting burnout from physicians to practice staff, ensure that staff who assume new responsibilities are well-trained and understand that they are contributing to the health of their patients and that unnecessary work is reengineered out of the practice $^{2,39}$

In the longer run, to address the chasm between society's expectations and primary care's capacity, more financial and personnel resources should be dedicated to primary care. One study estimates that a 59\% increase in staffing, to 4.25 FTE staff per physician, is needed to achieve the patient-centered medical home. ${ }^{40}$

\section{Patient-centeredness and the Fourth Aim}

The barriers to achieving the Triple Aim include improving population health in a society experiencing obesity and diabetes epidemics and growing income disparities, rising health care costs, and a dispirited and disengaged health care workforce. If the gap continues to widen between society's expectations for primary care and primary care's available resources, the feelings of betrayal and the wearing down from daily stress voiced by primary care practitioners will grow. The negative impact on patient-centered care will be deep and long lasting. On the other hand, if an emphasis on the workforce comes at the expense of patients' needs, this focus could have negative consequences. Health care is a relationship between those who provide care and those who seek care, a relationship that can only thrive if it is symbiotic, benefiting both parties.

\section{CONCLUSION}

The Triple Aim has provided society with a compass, pointing the way forward for our health care system. The positive engagement, rather than the negative frustration, of the health care workforce is of paramount importance in achieving the primary goal of the Triple Aim-improving population health. Leaders and providers of health care should consider adding a fourth dimension-improving the work life of those who deliver care-to the compass points of better care, better health, and lower costs.

To read or post commentaries in response to this article, see it online at http://www.annfammed.org/content/12/6/573

Key words: primary health care; patient-centered care; health care workforce

Submitted May 10, 2014 ; submitted, revised August 15, 2014; accepted September 2, 2014.

\section{REFERENCES}

1. Berwick DM, Nolan TW, Whittington J. The Triple Aim: care, health, and cost. Health Aff (Millwood). 2008;27(3):759-769. 
2. Sinsky CA, Willard-Grace R, Schutzbank AM, Sinsky TA, Margolius $D$, Bodenheimer $T$. In search of joy in practice: a report of 23 high-functioning primary care practices. Ann Fam Med. 2013;11(3): 272-278.

3. Detsky AS. What patients really want from health care. JAMA. 2011; 306(22):2500-2501.

4. Berwick DM. What 'patient-centered' should mean: confessions of an extremist. Health Aff (Millwood). 2009;28(4):w555-w565.

5. Shanafelt TD, Boone $S$, Tan $L$, et al. Burnout and satisfaction with work-life balance among US physicians relative to the general US population. Arch Intern Med. 2012;172(18):1377-1385.

6. Kane L, Peckham C. Medscape Physician Compensation Report 2014. http://www.medscape.com/features/slideshow/compensation/2014/public/overview\#24. accessed Jul 15, 2014.

7. Friedberg MW, Chen PG, Van Busum KR, et al. Factors affecting physician professional satisfaction and their implications for patient care, health systems and health policy. Rand Corporation 2013. http://www.rand.org/content/dam/rand/pubs/research_reports/ RR400/RR439/RAND_RR439.pdf. Accessed Jul 15, 2014.

8. 2011 Physician Stress and Burnout Survey. Physician Wellness Services and Cejka Search. http://www.cejkasearch.com/wp-content/ uploads/physician-stress-burnout-survey.pdf. Accessed Jul 15, 2014

9. The Second Annual Practice Profitability Index. 2014 Edition. CareCloud. http://on.carecloud.com/rs/carecloud/images/PPI-Report.pdf. Accessed Aug 14. 2014.

10. Arndt B, Tuan W-J, White J, Schumacher J. Panel workload assessment in US primary care: accounting for non-face-to-face panel management activities. J Am Board Fam Med. 2014;27(4):530-537.

11. Montague E, Asan O. Physician interactions with electronic health records in primary care. Health Syst (Basingstoke). 2012;1(2):96-103.

12. Murphy DR, Reis B, Sittig DF, Singh H. Notifications received by primary care practitioners in electronic health records: a taxonomy and time analysis. Am J Med. 2012;125(2):209.e1-209.e7.

13. Murphy DR, Reis $B$, Kadiyala $H$, et al. Electronic health recordbased messages to primary care providers: valuable information or just noise? Arch Intern Med. 2012;172(3):283-285.

14. Hill RG Jr, Sears LM, Melanson SW. 4000 clicks: a productivity analysis of electronic medical records in a community hospital ED. Am J Emerg Med. 2013;31(11):1591-1594.

15. Jamoom E, Patel V, King J, Furukawa MF. Physician experience with electronic health record systems that meet meaningful use criteria: NAMCS Physician Workflow Survey, 2011. NCHS data brief, no 129. Hyattsville, MD: National Center for Health Statistics. 2013.

16. McHugh MD, Kutney-Lee A, Cimiotti JP, Sloane DM, Aiken LH. Nurses' widespread job dissatisfaction, burnout, and frustration with health benefits signal problems for patient care. Health Aff (Millwood). 2011;30(2):202-210.

17. Dixon CAJ, Tompkins CNE, Allgar VL, Wright NMJ. Abusive behaviour experienced by primary care receptionists: a cross-sectional survey. Fam Pract. 2004;21(2):137-139.

18. Eisner M, Britten N. What do general practice receptionists think and feel about their work? Br J Gen Pract. 1999;49(439):103-106.

19. CareerBuilder press release, April 30, 2013. More than one third of employed health care workers plan to look for a new job this year. http://www.careerbuilder.com/share/aboutus/pressreleases.aspx. Accessed May 1, 2014

20. Caffarini K. How to help medical practice staff avoid burnout. Am Med News. June 10, 2013. http://www.amednews.com/ article/20130610/business/130619992/5/.
21. Haas JS, Cook EF, Puopolo AL, Burstin HR, Cleary PD, Brennan TA. Is the professional satisfaction of general internists associated with patient satisfaction? J Gen Intern Med. 2000;15(2):122-128.

22. Kushnir T, Greenberg D, Madjar N, Hadari I, Yermiahu Y, Bachner YG. Is burnout associated with referral rates among primary care physicians in community clinics? Fam Pract. 2014;31(1):44-50.

23. Bachman KH, Freeborn DK. HMO physicians' use of referrals. Soc Sci Med. 1999;48(4):547-557.

24. Sirovich BE, Woloshin S, Schwartz LM. Too Little? Too Much? Primary care physicians' views on US health care: a brief report. Arch Intern Med. 2011;171(17):1582-1585.

25. Buchbinder SB, Wilson M, Melick CF, Powe NR. Primary care physician job satisfaction and turnover. Am J Manag Care. 2001;7(7): 701-713.

26. Williams ES, Skinner AC. Outcomes of physician job satisfaction: Williams ES, Skinner AC. Outcomes of physician job satisfaction: a narrative review, implications, and directions for future research. Health Care Manage Rev. 2003;28(2):119-139.

27. DiMatteo MR, Sherbourne CD, Hays RD, et al. Physicians' characteristics influence patients' adherence to medical treatment: results from the Medical Outcomes Study. Health Psychol. 1993;12(2):93-102.

28. Hojat M, Louis DZ, Markham FW, Wender R, Rabinowitz C, Gonnella JS. Physicians' empathy and clinical outcomes for diabetic patients. Acad Med. 2011;86(3):359-364.

29. Spinelli WM. The phantom limb of the triple aim. Mayo Clin Proc. 2013;88(12):1356-1357.

30. Lewis SE, Nocon RS, Tang H, et al. Patient-centered medical home characteristics and staff morale in safety net clinics. Arch Intern Med. 2012;172(1):23-31.

31. Babbott S, Manwell LB, Brown R, et al. Electronic medical records and physician stress in primary care: results from the MEMO Study. J Am Med Inform Assoc. 2014;21(e1):e100-e106.

32. Reid RJ, Coleman K, Johnson EA, et al. The Group Health medical home at year two: cost savings, higher patient satisfaction, and less burnout for providers. Health Aff (Millwood). 2010;29(5):835-843.

33. Bodenheimer $T$, Willard-Grace $R$, Ghorob A. Expanding the roles of medical assistants: who does what in primary care? JAMA Intern Med. 2014;174(7):1025-1026.

34. Reuben DB, Knudsen J, Senelick W, Glazier E, Koretz BK. The effect of a physician partner program on physician efficiency and patient satisfaction. JAMA Intern Med. 2014;174(7):1190-1193.

35. Sinsky CA, Sinsky TA. Test result follow-up: a systematic review. J Gen Intern Med. 2013;28(2):174.

36. Bodenheimer TS, Smith MD. Primary care: proposed solutions to the physician shortage without training more physicians. Health Aff (Millwood). 2013;32(11):1881-1886.

37. Sinsky TA, Sinsky CA. A streamlined approach to prescription management. Fam Pract Manag. 2012;19(6):11-13.

38. Shipman SA, Sinsky CA. Expanding primary care capacity by reducing waste and improving the efficiency of care. Health Aff (Millwood). 2013;32(11):1990-1997.

39. Willard R, Bodenheimer T. The building blocks of high-performing primary care: lessons from the field. California HealthCare Foundation, 2012. http://www.chcf.org/publications/2012/04/ building-blocks-primary-care.

40. Patel MS, Arron MJ, Sinsky TA, et al. Estimating the staffing infrastructure for a patient-centered medical home. Am J Manag Care. 2013;19(6):509-516. 